\title{
Weed infestation of winter wheat continuous cropping after implementation of catch crop and biostimulant Nano-Gro
}

\section{Zachwaszczenie monokultury pszenicy ozimej po zastosowaniu międzyplonu ścierniskowego i biostymulatora Nano-Gro}

\author{
Danuta Parylak*, Elżbieta Pytlarz
}

\begin{abstract}
Summary
One-factorial field experiment was conducted in 2010-2014 at Wrocław University of Environmental and Life Sciences. The aim of the research was to investigate the response of winter wheat to continuous cropping method and to determine the effect of catch crop and biostimulant on weed infestation under conventional or reduced post-harvest and pre-sowing soil tillage. In continuous cropping there was a significant increase in the number of weeds (3-fold) together with reduced number of species by $30 \%$ in relation to crop rotation. Plowing down white mustard or plowing it down with subsequent use of biostimulant Nano-Gro caused significant reduction in weed infestation respectively by 50 and $36 \%$ in comparison with continuous cropping without regenerative treatment. Simplifying soil tillage reduced weed infestation by $39 \%$ only after incorporation with soil biomass of catch crop. Nano-Gro was ineffective in reducing weed infestation, it even caused increase in weed number under reduced tillage by $35 \%$.
\end{abstract}

Key words: winter wheat; continuous cropping; biostimulant; catch crop; weed infestation; cropping system

\section{Streszczenie}

Jednoczynnikowe doświadczenie polowe zrealizowano w latach 2010-2014 w Uniwersytecie Przyrodniczym we Wrocławiu. Celem badań było poznanie reakcji pszenicy ozimej na uprawę monokulturową oraz określenie wpływu międzyplonu ścierniskowego i biostymulatora na zachwaszczenie łanu w warunkach tradycyjnej lub uproszczonej pożniwnej i przedsiewnej uprawy roli. W monokuluturze w stosunku do płodozmianu wykazano istotny 3-krotny wzrost liczby chwastów oraz ograniczenie liczby gatunków o $30 \%$. W systemie płużnym przyorywanie gorczycy białej oraz jej łączne stosowanie z biostymulatorem Nano-Gro przyczyniło się do istotnego ograniczenia zachwaszczenia odpowiednio o 50 i 36\% w porównaniu z monokulturą bez zabiegów regeneracyjnych. Po uproszczeniu uprawy roli ograniczenie zachwaszczenia (o $39 \%$ ) stwierdzono wyłącznie po wprowadzeniu do gleby biomasy międzyplonu. Użycie Nano-Gro okazało się nieskuteczne w ograniczeniu zachwaszczenia, a po uproszczeniach w uprawie roli obserwowano wzrost liczby chwastów o 35\%.

Słowa kluczowe: pszenica ozima; monokultura; biostymulator; międzyplon ścierniskowy; zachwaszczenie; system uprawy

\footnotetext{
Uniwersytet Przyrodniczy we Wrocławiu

Katedra Kształtowania Agroekosystemów i Terenów Zieleni

PI. Grunwaldzki 24A, 50-363 Wrocław

*corresponding author: danuta.parylak@up.wroc.pl
} 


\section{Wstęp / Introduction}

Pogarszająca się efektywność ekonomiczna gospodarstw rolnych skłania plantatorów do ograniczania nakładów związanych z konwencjonalną uprawą roli oraz do wzrostu udziału roślin zbożowych w zmianowaniu (Starczewski i wsp. 2004; Giemza-Mikoda i wsp. 2012). Uproszczenia w uprawie roli oraz koncentracja roślin kłosowych w strukturze zasiewów ze znaczącym udziałem pszenicy mogą sprzyjać rozwojowi niektórych gatunków chwastów, w szczególności z rodziny traw (Parylak 2005; Dorado i Lopez-Fando 2006; Ramsdale i wsp. 2006). Wzrostowi zachwaszczenia oraz kompensacji niektórych gatunków chwastów w monokulturze zbóż można przeciwdziałać stosując przerywniki w postaci międzyplonów (Legere i wsp. 2005; Parylak 2005; Wojciechowski 2009). Nowatorskim rozwiązaniem jest wykorzystanie biostymulatorów zwiększających tolerancję roślin uprawnych na warunki stresowe (Pruszyński 2008; Jaskulski i wsp. 2012). Jednym z takich preparatów jest stymulator wzrostu i plonowania roślin Nano-Gro, który - zdaniem producenta - podwyższa naturalną odporność roślin w warunkach stresu abiotycznego.

Hipoteza badawcza zakładała, że zastosowanie zabiegów o charakterze regeneracyjnym wzmocni kondycję rośliny uprawnej, a w efekcie poprawi się jej konkurencyjność wobec chwastów.

Celem badań było określenie wpływu corocznego przyorywania międzyplonu ścierniskowego z gorczycy białej i stosowania biostymulatora Nano-Gro na zachwaszczenie łanu pszenicy ozimej w monokulturze w warunkach tradycyjnej lub uproszczonej pożniwnej i przedsiewnej uprawy roli.

\section{Materiały i metody / Materials and methods}

Badania zrealizowano w oparciu o ścisłe jednoczynnikowe doświadczenie polowe, które przeprowadzono w latach 2010-2014 w Rolniczym Zakładzie Doświadczalnym Swojec Uniwersytetu Przyrodniczego we Wrocławiu. Doświadczenie założono metodą losowanych bloków w trzech powtórzeniach, na poletkach o powierzchni $22 \mathrm{~m}^{2}$, na madzie rzecznej właściwej o słabo wykształconym profilu, wytworzonej z piasku gliniastego mocnego na utworze $\mathrm{z}$ piasku słabo gliniastego, zaliczanej do kompleksu żytniego dobrego klasy IVa. W doświadczeniu analizowano skutki uprawy pszenicy ozimej odmiany Natula bezpośrednio po sobie w stosunku do płodozmianu (rzepak ozimy - pszenica ozima - jęczmień jary). Badano także skuteczność ograniczania zachwaszczenia w fazie krzewienia (BBCH 22-25) po zastosowaniu różnych systemów uprawy w monokulturze, na które złożyły się: zróżnicowanie uprawy pożniwnej i przedsiewnej oraz zabiegi regeneracyjne poprawiające warunki siedliskowe i kondycję rośliny uprawnej (tj. przyorywanie międzyplonu ścierniskowego $\mathrm{z}$ gorczycy białej, zaprawianie ziarna biostymulatorem Nano-Gro w dawce 24 granulki Nano-Gro/10 1 wody/1 t ziarna lub łączne stosowanie tych zabiegów). Nano-Gro to organiczny stymulator wzrostu roślin, który jednocześnie indukuje ich odporność. Skład- nikiem preparatu są siarczany: $\mathrm{Fe}, \mathrm{Co}, \mathrm{Al}, \mathrm{Mg}, \mathrm{Mn}, \mathrm{Ni}, \mathrm{Ag}$ w stężeniu $10^{-9}$ mola oraz cukier oczyszczony metanolem (1000 g cukru/20 ml alkoholu). Po zbiorze przedplonu wykonywano podorywkę na głębokość $10 \mathrm{~cm}$ albo kultywatorowanie połączone $\mathrm{z}$ bronowaniem pielęgnacyjnym. Uprawę przedsiewną realizowano wykonując orkę siewną na głębokość $20 \mathrm{~cm}$ lub upraszczano ją wykorzystując jedynie agregat uprawowy. Pszenicę, niezależnie od systemu uprawy, wysiewano w ilości $230 \mathrm{~kg} / \mathrm{ha}$. Jesienią, po wschodach pszenicy, chwasty zwalczano wykonując opryskiwanie całego pola herbicydem Maraton 375 SC w dawce 4 1/ha.

Ocenę zachwaszczenia przeprowadzono wiosną bezpośrednio przed wykonaniem kolejnego zabiegu herbicydowego (pszenica w fazie BBCH 22-25) w dwóch powtórzeniach na poletku na powierzchni $0,2 \mathrm{~m}^{2}$. Badania obejmowały określenie składu gatunkowego chwastów oraz liczebność poszczególnych gatunków. Uzyskane wyniki badań poddano analizie wariancji, a istotność różnic między średnimi oceniano testem Tukeya na poziomie istotności $\alpha=0,05 \mathrm{z}$ wykorzystaniem programu FR-ANALWAR.

\section{Wyniki i dyskusja / Results and discussion}

W wyniku przeprowadzonych badań stwierdzono istotny wpływ następstwa roślin na stopień zachwaszczenia pszenicy ozimej w fazie krzewienia (rys. 1). Uprawa monokulturowa doprowadziła do istotnego, 3-krotnego zwiększenia liczby chwastów oraz ograniczenia występujących gatunków o 30\% w stosunku do uprawy pszenicy w płodozmianie, co potwierdzają także badania Blecharczyka i wsp. (2007), Feledyn-Szewczyk i Duer (2007) oraz Kwiatkowskiego (2009). We wcześniejszych badaniach Duer i Feledyn-Szewczyk (2003) stwierdziły natomiast mniejszą obsadę chwastów w monokulturze pszenicy ozimej niż w zmianowaniu.

Wykazano również istotne różnice w liczbie chwastów w zależności od systemu uprawy pszenicy w monokulturze (tab. 1). W systemie płużnym uzyskano wyraźną redukcję zachwaszczenia po przyoraniu międzyplonu ścierniskowego oraz po łącznym stosowaniu międzyplonu z biostymulatorem Nano-Gro odpowiednio o 50 i $36 \%$ w odniesieniu do poletek bez zabiegów regeneracyjnych. Również Kraska i wsp. (2014) odnotowali ograniczenie zachwaszczenia pszenicy jarej po wcześniejszym przyoraniu gorczycy białej. Zastąpienie podorywki kultywatorowaniem przyczyniło się do zmniejszenia konkurencyjności pszenicy ozimej wobec chwastów. Mimo to w warunkach uprawy zredukowanej do kultywatorowania obecność międzyplonu ścierniskowego okazała się przydatna $\mathrm{w}$ istotnej redukcji zachwaszczenia $\mathrm{w}$ odniesieniu do monokultury bez zabiegów regeneracyjnych. Upraszczanie uprawy roli prowadziło natomiast do wzrostu zachwaszczenia po użyciu biostymulatora, a szczególnie po jego stosowaniu łącznie $\mathrm{z}$ międzyplonem ścierniskowym odpowiednio o 35 i $65 \%$ w porównaniu do poletek z tymi samymi zabiegami regeneracyjnymi, ale w uprawie płużnej. Zdaniem Matysiak i Kaczmarek (2008) oraz Grzysia (2012) ograniczona rola biostymulatora $\mathrm{w}$ redukcji zach- 
waszczenia, mimo zakładanej poprawy kondycji pszenicy, może wynikać ze sposobu jego aplikacji na roślinę. Po łącznym zastosowaniu biostymulatora Nano-Gro z gorczycą białą, mających poprawić kondycję pszenicy ozimej, nie stwierdzono istotnego wpływu na zachwaszczenie w warunkach uproszczonej pożniwnej i przedsiewnej uprawy roli $\mathrm{w}$ porównaniu $\mathrm{z}$ monokulturą bez zabiegów regeneracyjnych.
Uprawa pszenicy w monokulturze zwiększyła ponad 3-krotnie występowanie gatunków jednoliściennych w stosunku do płodozmianu (rys. 2). Zdaniem Dorado i Lopez-Fando (2006) zwiększony udział roślin kłosowych $\mathrm{w}$ zmianowaniu sprzyja rozwojowi gatunków $\mathrm{z}$ rodziny Poaceae. Tezę tę potwierdzają badania Parylak (2005), która dowiodła, że skrajne uproszczenie zmianowania prowadziło do dominacji Apera spica-venti. Również

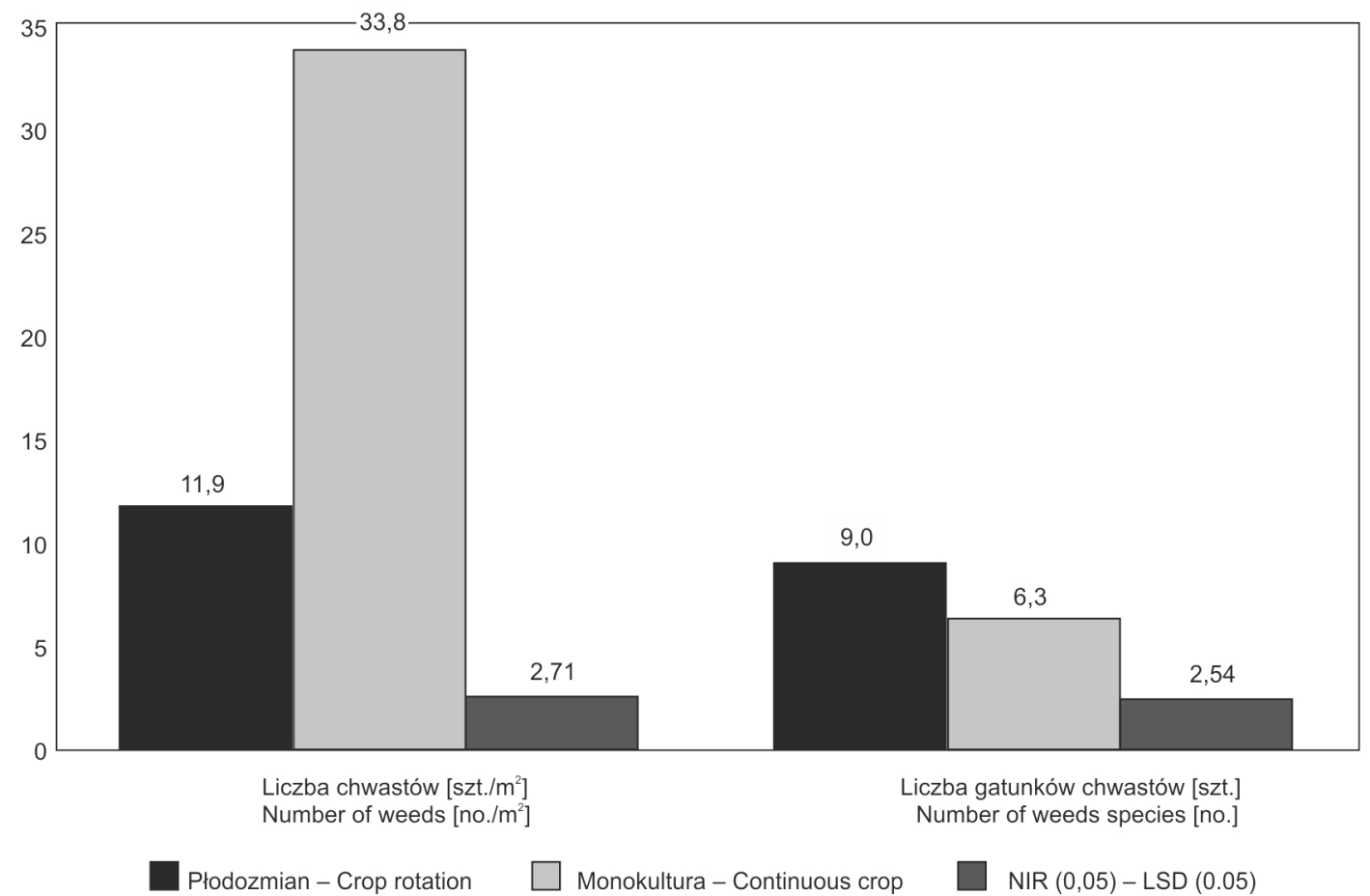

Rys. 1. Wpływ następstwa roślin na zachwaszczenie pszenicy ozimej

Fig. 1. Influence of crop succession on weed infestation in winter wheat

Tabela 1. Wpływ zabiegów regeneracyjnych na liczbę chwastów w łanie pszenicy ozimej ( $\mathrm{P}$ - płodozmian, $\mathrm{M}$ - monokultura) Table 1. Influence of regenerative treatment on the number of weeds in winter wheat ( - crop rotation, $\mathrm{M}-$ continuous crop)

\begin{tabular}{|c|c|c|c|c|}
\hline \multicolumn{4}{|c|}{ System uprawy - Cropping system } & \multirow{2}{*}{$\begin{array}{l}{\left[\mathrm{szt} . / \mathrm{m}^{2}\right]} \\
{\left[\mathrm{no} . / \mathrm{m}^{2}\right]}\end{array}$} \\
\hline $\begin{array}{l}\text { Następstwo roślin } \\
\text { Crop succession }\end{array}$ & $\begin{array}{l}\text { uprawa pożniwna } \\
\text { post-harvest tillage }\end{array}$ & $\begin{array}{l}\text { zabieg regeneracyjny } \\
\text { regenerative treatment }\end{array}$ & $\begin{array}{l}\text { uprawa przedsiewna } \\
\text { pre-sowing tillage }\end{array}$ & \\
\hline$P$ & $\begin{array}{l}\text { orka } \\
\text { plough }\end{array}$ & - & $\begin{array}{c}\text { orka } \\
\text { plough }\end{array}$ & 11,9 \\
\hline $1 \mathrm{M}$ & $\begin{array}{l}\text { orka } \\
\text { plough }\end{array}$ & - & $\begin{array}{l}\text { orka } \\
\text { plough }\end{array}$ & 33,8 \\
\hline $2 \mathrm{M}$ & $\begin{array}{l}\text { orka } \\
\text { plough }\end{array}$ & $\begin{array}{l}\text { międzyplon ścierniskowy } \\
\text { stubble catch crop }\end{array}$ & $\begin{array}{l}\text { orka } \\
\text { plough }\end{array}$ & 16,9 \\
\hline $3 \mathrm{M}$ & $\begin{array}{l}\text { orka } \\
\text { plough }\end{array}$ & $\begin{array}{c}\text { biostymulator } \\
\text { biostimulant }\end{array}$ & $\begin{array}{c}\text { orka } \\
\text { plough }\end{array}$ & 32,6 \\
\hline $4 \mathrm{M}$ & $\begin{array}{c}\text { orka } \\
\text { plough }\end{array}$ & $\begin{array}{l}\text { międzyplon ścierniskowy + biostymulator } \\
\text { stubble catch crop + biostimulant }\end{array}$ & $\begin{array}{c}\text { orka } \\
\text { plough }\end{array}$ & 21,7 \\
\hline $5 \mathrm{M}$ & $\begin{array}{l}\text { kultywatorowanie } \\
\text { cultivating }\end{array}$ & $\begin{array}{l}\text { międzyplon ścierniskowy } \\
\text { stubble catch crop }\end{array}$ & $\begin{array}{l}\text { uprawa agregatem } \\
\text { harrow }\end{array}$ & 20,7 \\
\hline $6 \mathrm{M}$ & $\begin{array}{l}\text { kultywatorowanie } \\
\text { cultivating }\end{array}$ & $\begin{array}{c}\text { biostymulator } \\
\text { biostimulant }\end{array}$ & $\begin{array}{l}\text { uprawa agregatem } \\
\text { harrow }\end{array}$ & 44,1 \\
\hline $7 \mathrm{M}$ & $\begin{array}{l}\text { kultywatorowanie } \\
\text { cultivating }\end{array}$ & $\begin{array}{l}\text { międzyplon ścierniskowy + biostymulator } \\
\text { stubble catch crop + biostimulant }\end{array}$ & $\begin{array}{l}\text { uprawa agregatem } \\
\text { harrow }\end{array}$ & 35,7 \\
\hline \multicolumn{4}{|l|}{$\operatorname{NIR}(0,05)-\operatorname{LSD}(0.05)$} & 5,15 \\
\hline
\end{tabular}




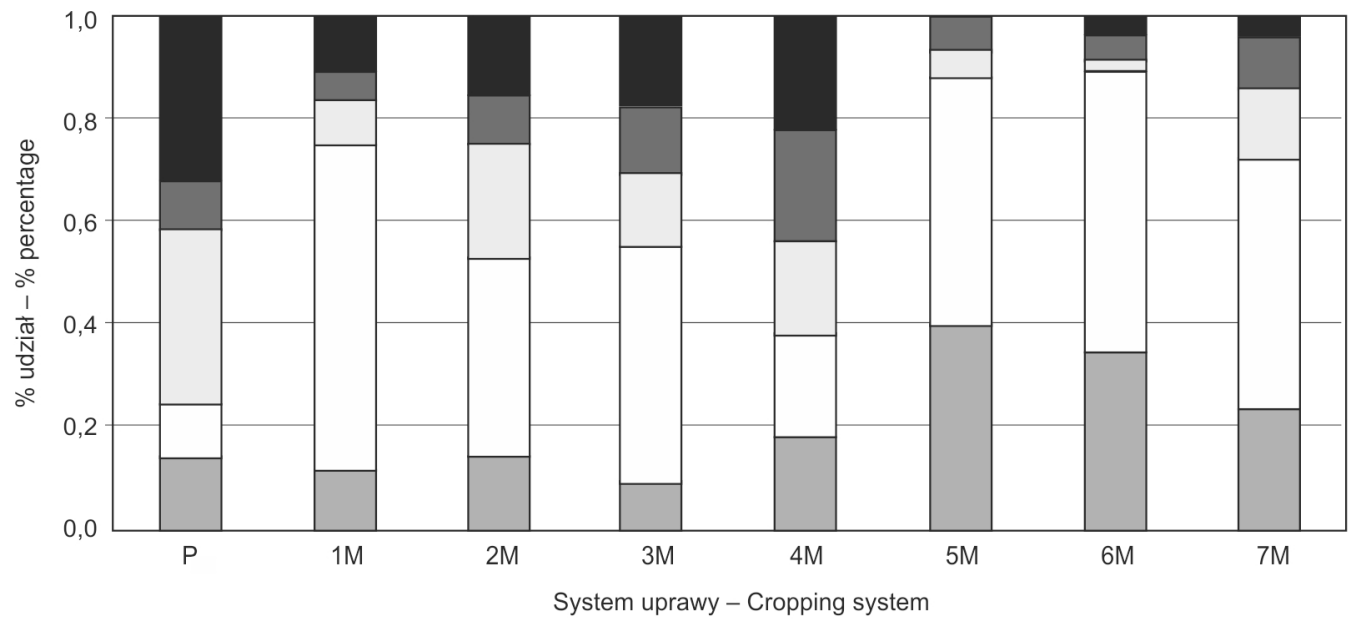

Echinochloa crus-galit

Aspera spica-venti

Viola arvensis

Veronica persica

Pozostałe - Other

Rys. 2. Udział ważniejszych gatunków chwastów w ogólnej liczbie chwastów w łanie pszenicy ozimej

Fig. 2. Percentage of the most important species of weeds on the total number of weeds in winter wheat

badania Blecharczyka i wsp. (2007) wskazują na zwiększone zachwaszczenie $A$. spica-venti po zastąpieniu płodozmianu uprawą monokulturową. Szczególnie wyraźną dominację gatunków jednoliściennych spowodowało uproszczenie pożniwnej i przedsiewnej uprawy roli. Najwyższą skuteczność w ograniczeniu zachwaszczenia A. spica-venti, zarówno w systemie płużnym, jak i uproszczonym z użyciem kultywatora i agregatu uprawowego, uzyskano po zastosowaniu kombinacji międzyplonu ścierniskowego $\mathrm{z}$ biostymulatorem. Badania własne potwierdziły także doniesienie Sekutowskiego (2007) o zmniejszeniu liczebności Viola arvensis po zastosowaniu uproszczeń w uprawie roli. W składzie pozostałych, nielicznie występujących dwuliściennych gatunków (Capsella bursa-pastoris, Galium aparine, Geranium pusillum, Lycopsis arvensis oraz Veronica persica) nie obserwowano wyraźnych zmian pod wpływem czynników doświadczenia.

Nie stwierdzono korelacji między stopniem zachwaszczenia a plonem pszenicy ozimej.

\section{Wnioski / Conclusions}

1. Uprawa pszenicy ozimej w monokulturze, w stosunku do uprawy w płodozmianie rzepak ozimy - pszenica ozima - jęczmień jary, spowodowała istotny (prawie 3-krotny) wzrost liczby chwastów, ale ograniczenie liczby gatunków (o 30\%).

2. W monokulturze coroczne przyorywanie międzyplonu ścierniskowego z gorczycy białej skutecznie ograniczało zachwaszczenie łanu pszenicy w fazie krzewienia, zarówno w warunkach tradycyjnej, jak i uproszczonej uprawy roli, odpowiednio o 50 i $39 \%$.

3. Zaprawianie ziarna biostymulatorem Nano-Gro w celu poprawy kondycji pszenicy ozimej w monokulturze okazało się nieskuteczne w zwiększeniu konkurencyjności zboża względem chwastów, a po zastąpieniu orki kultywatorowaniem obserwowano wręcz wzrost zachwaszczenia.

4. W monokulturze pszenicy ozimej, szczególnie po zastosowaniu uproszczeń w uprawie roli, dominowały gatunki jednoliścienne, takie jak: Echinochloa crusgalli i A. spica-venti.

\section{Literatura / References}

Blecharczyk A., Małecka I., Zawada D., Sawinska Z. 2007. Bioróżnorodność chwastów w pszenicy ozimej w zależności od wieloletniego nawożenia i systemu następstwa roślin. Fragmenta Agronomica 24 (3): 27-33.

Dorado J., Lopez-Fando C. 2006. The effect of tillage system and use of a paraplow on weed flora in a semiarid soil from central Spain. Weed Research 46 (5): 424-431.

Duer I., Feledyn-Szewczyk B. 2003. Skład gatunkowy i biomasa chwastów występujących w pszenicy ozimej uprawianej w różnych systemach produkcji oraz ich udział w pobieraniu składników mineralnych z gleby. [Species composition and biomass of weeds in winter wheat cultivated under different crop production systems and their contribution to the uptake of mineral components from the soil]. Pamiętnik Puławski 134: 65-77.

Feledyn-Szewczyk B., Duer I. 2007. Podobieństwo glebowego banku nasion i aktualnego zachwaszczenia łanu pszenicy ozimej w różnych systemach produkcji rolnej. Annales Universitatis Mariae Curie-Skłodowska, Sectio E, Agricultura 62 (2): $157-167$.

Giemza-Mikoda M., Zimny L., Wacławowicz R. 2012. Wpływ systemów uprawy na zachwaszczenie jęczmienia jarego. [The influence of cultivation systems on weed infestation in spring barley]. Progress in Plant Protection/Postępy w Ochronie Roślin 52 (2): $283-286$.

Grzyś E. 2012. Wpływ wybranych substancji biologicznie czynnych na kukurydzę uprawianą w warunkach stresu. Wydawnictwo Uniwersytetu Przyrodniczego we Wrocławiu, Monografia 145, 101 ss. 
Jaskulski D., Kotwica K., Jaskulska I., Piekarczyk M., Osiński G., Pochylski B. 2012. Elementy współczesnych systemów uprawy roli i roślin - skutki produkcyjne oraz środowiskowe. [Components of today's tillage and crop farming systems - production and environmental effects]. Fragmenta Agronomica 29 (3): 61-70.

Kraska P., Andruszczak S., Kwiecińska-Poppe E., Pałys E. 2014. Tillage systems and catach crops as factors determining weed infestation level in a spring wheat canopy (Triticum aestivum L.) sown in monoculture. Acta Scientarum Polonorum, Agricultura 13 (2): $33-50$.

Kwiatkowski C. 2009. Struktura zachwaszczenia i produkcyjność biomasy pszenicy ozimej oraz chwastów w zależności od systemu następstwa roślin i sposobu pielęgnacji. Annales Universitatis Mariae Curie-Skłodowska, Sectio E, Agricultura 64 (3): 69-78.

Legere A., Stevenson F.C., Benoit D.L. 2005. Diversity and assembly of weed communities: contrasting responses cross cropping systems. Weed Research 45 (3): 303-315.

Matysiak K., Kaczmarek S. 2008. Potential advantages of Kelpak bioregulator applied to some field crops. p. 99-106. In: "Biostimulators in modern agriculture. Field crops" (Z.T. Dąbrowski, ed.). Wieś Jutra, Warszawa, 118 pp.

Parylak D. 2005. Zachwaszczenie pszenicy ozimej uprawianej po sobie z zastosowaniem uproszczeń w uprawie roli. [Weed infestation of continuous crop winter wheat under reduced tillage]. Progress in Plant Protection/Postępy w Ochronie Roślin 45 (1): $357-362$.

Pruszyński S. 2008. Biostimulators in plant protection. p. 18-23. In: "Biostimulators in modern agriculture. General aspect" (H. Gawrońska, ed.). Wieś Jutra, Warszawa, 89 pp.

Ramsdale B., Kegode G., Messersmith C., Nalewaja J., Nord C. 2006. Long term effects of spring wheat-soybean cropping systems on weed populations. Field Crops Research 97: 197-208.

Sekutowski T. 2007. Wpływ technologii uprawy i ochrony herbicydowej na wysokość plonu pszenicy ozimej uprawianej w monokulturze. Inżynieria Rolnicza 3 (91): 159-166.

Starczewski J., Czarnocki Sz., Turska E. 2004. Alternatywne sposoby uprawy roli i ich ekonomiczna ocena. Annales Universitatis Mariae Curie-Skłodowska, Sectio E, Agricultura 59: 277-284.

Wojciechowski W. 2009. Znaczenie międzyplonów ścierniskowych w optymalizacji nawożenia azotem jakościowej pszenicy jarej. Monografie Uniwersytetu Przyrodniczego we Wrocławiu, 122 ss. 